\title{
Global to Small Island; A Cross-Scale Foresight Scenario Exercise
}

\begin{tabular}{|r|l|}
\hline Journal: & Foresight \\
\hline Manuscript ID & fs-02-2020-0012.R1 \\
\hline Manuscript Type: & Original Article \\
\hline Keywords: & $\begin{array}{l}\text { foresight, cross-scale scenarios, multiscale scenarios, small island } \\
\text { developing states (SIDS), climate change, water demand }\end{array}$ \\
\hline \multicolumn{2}{|l}{} \\
\hline
\end{tabular}

\section{SCHOLARONE \\ Manuscripts}




\section{MANUSCRIPT DETAILS: Global to Small Island; A Cross-Scale Foresight Scenario Exercise}

: use of socio-economic scenarios in Small Island Developing States (SIDS) when assessing, and planning for, the impacts of global changes on national socioeconomic and environmental systems is still in its infancy. The research conducts a cross-scale foresight scenario exercise to produce regional scenarios and national storylines for Caribbean islands that are of â€ partialâ€ $€^{\mathrm{TM}}$ consistency to the Shared Socioeconomic Pathways (SSPs) and Representative Concentration Pathways (RCPs); and shows how future socioeconomic and climatic changes can be applied to inform natural resource management decisions.develop the scenarios the study uses a three-staged linking process using mixed methods to â€œtriangulateâ€? each technique to compensate for weaknesses of one method by introducing a complementary method at each stage. A participatory-expert stepwise approach with feedback loops is employed and complemented with a climate sensitive tourism water demand model.regional exploratory socio-economic scenarios were constructed that are partially consistent with global scenarios. In addition, national storylines for four island states were developed based on the regional scenarios. Using RCP 4.5 hotel water demand in Barbados is estimated under three of the regional scenarios based on compatibility. The results indicate there is a $17 \%$ difference between the highest and lowest estimated water demand, indicating the effect of varying socio-economic conditions on water demand._RESEARCH_LIMITATIONS/IMPLICATIONS_(LIMIT_100_WORDS) :No data available._PRACTICAL_IMPLICATIONS_(LIMIT_100_WORDS) :No data available.paper contributes to the literature by presenting regional socio-economic scenarios specifically for SIDS, that are partially consistent with both global climatic (RCPs) and socio-economic pathways (SSPs) using a cross-scale approach. The scenarios are then used to demonstrate how future socioeconomic pathways impact on freshwater demand. 


\title{
Global to Small Island; A Cross-Scale Foresight Scenario Exercise
}

\begin{abstract}
Purpose - The use of socio-economic scenarios in Small Island Developing States (SIDS) when assessing, and planning for, the impacts of global changes on national socioeconomic and environmental systems is still in its infancy. The research conducts a cross-scale foresight scenario exercise to produce regional scenarios and national storylines for Caribbean islands that are of 'partial' consistency to the Shared Socioeconomic Pathways (SSPs) and Representative Concentration Pathways (RCPs); and shows how future socioeconomic and climatic changes can be applied to inform natural resource management decisions.
\end{abstract}

Design/methodology/approach - To develop the scenarios the study uses a three-staged linking process using mixed methods to "triangulate" each technique to compensate for weaknesses of one method by introducing a complementary method at each stage. A participatory-expert stepwise approach with feedback loops is employed and complemented with a climate sensitive tourism water demand model.

Findings - Four regional exploratory socio-economic scenarios were constructed that are partially consistent with global scenarios. In addition, national storylines for four island states were developed based on the regional scenarios. Using RCP 4.5 hotel water demand in Barbados is estimated under three of the regional scenarios based on compatibility. The results indicate there is a $17 \%$ difference between the highest and lowest estimated water demand, indicating the effect of varying socio-economic conditions on water demand.

Originality - The paper contributes to the literature by presenting regional socio-economic scenarios specifically for SIDS, that are partially consistent with both global climatic (RCPs) and socio-economic pathways (SSPs) using a cross-scale approach. The scenarios are then used to demonstrate how future socioeconomic pathways impact on freshwater demand.

Paper type- Research/Case study

Key words - foresight, cross-scale scenarios, multiscale scenarios, small island developing states (SIDS), climate change, water demand 


\section{Introduction}

Climate studies have shown that for the Caribbean impacts of climate change on social economic and environmental systems are likely to be far ranging and detrimental (Cashman, et al., 2009; Rhiney, 2015; Robinson, 2018; Taylor, et al., 2018). Extreme events, such as hurricanes and droughts, have demonstrated the vulnerability of the region and the breadth of developmental decisions that are needed to build resilience. The development of policies and investment programs forming the basis of adaptation and mitigation actions should be robust enough to respond to future conditions - climatic, social, economic and environmental. Therefore, there is an increasing need to develop 'no regret' actions that can accommodate uncertainty, and diverse plausible futures; decisions taken today must be fit-for-purpose for future decades.

The use of socio-economic scenarios to aid decision making has mushroomed in recent decades at various scales. At the global level there were a number of major initiatives from the late 1990s to the early 2000s, including the Global Scenario Group family (Gallopin \& Raskin, 1998; Raskin, 2008; Nakicenovic, et al., 2000), the IPCC Special Report on Emissions Scenarios (SRES), scenarios (MA Scenarios Working Group, 2005) and the various UNEP Global Environment Outlooks (UNEP, 2007; UNEP, 2010). More recently, greater acknowledgment has been given to the socio-economic component of climate scenarios, the Shared Socioeconomic Pathways (SSPs) (Kriegler, et al., 2014; O'Neill, et al., 2015). The SSPs are a set of foresight narratives that attempt to incorporate future uncertainty in global pathways. However, due to limitations such as data paucity and scarce technical capacity, global scenarios have been limited, inter alia, in their applicability to small island developing states (SIDS).

Despite SIDS being on the frontlines of a changing climate, there is a shortage of robust methods of how global scenarios can be translated to the localized cases of island states. At the global level, SIDS have championed the commitment to a $1.5^{\circ} \mathrm{C}$ compared to a $2^{\circ} \mathrm{C}$ rise in global temperature. Studies assuming a $1.5^{\circ} \mathrm{C}$ rise have demonstrated the concomitant adverse impact of associated extreme events such as floods, hurricanes and droughts as well as the extensive consequential social, environmental and economic threats to SIDS (Djalante, 2019). Worryingly, recent studies have suggested global temperatures may exceed a $2^{\circ} \mathrm{C}$ rise above pre-industrial levels (UNEP, 2019).

The future of SIDS economies and societies, under different climate scenarios has been the subject of limited investigation (Kelman \& West, 2009; UNFCCC, 2007; Vaha, 2018). Much of what has been reported was built on a foundation that was mostly anecdotal and ad hoc (Maze, 2019). This has pointed to the increasing need to construct robust socio-economic scenarios, with interlinkages to global climate change models (Perez-Soba \& Maas, 2015), to bolster the robustness of the messaging SIDS communicate to policymakers. Understanding potential future development paths and the options available to national and regional policymakers, is becoming more critical. Local conditions do not necessarily mirror those at the global level: in the 1990s, social democratic governments on continental Europe coexisted with neoliberal governments in the UK and US; and as those countries faced financial crisis, many economies in Asia and the Middle East were performing well. Yet, global trajectories and events constrain and inform, and therefore shape, local developments. It is therefore important to recognize, when developing cross-scale scenario narratives, that the connections underpinning them are fuzzy at best. 
In this study a scenario-based approach is developed to construct globally compatible regional exploratory scenarios for the English-speaking Caribbean ${ }^{1}$ SIDS (Figure 1) in the year 2050. These futures were developed to provide a greater understanding of what socio-economic possibilities could lie ahead for these independent island states within varying climatic conditions.

Figure 1: The Caribbean Region

In one sense, all scenario exercises are cross-scale, in that they capture the impact of factors external to a system or planning unit on that system or unit. However, dissatisfaction with the use of global scenarios for local studies (Wilbanks and Kates, 1999; Biggs, et al., 2007) has led to a spate of recent work on explicitly cross-scale scenarios (e.g., Kok, et al., 2007; Zurek \& Heinrichs, 2007; Stratigea \& Giaoutzi, 2012; Dermawan, et al., 2013). The approach is taken a step further by separately considering national (island) and regional (CARICOM) drivers in the context of a set of global scenarios. There is a need for such techniques, as illustrated by the three-level scenario methodology (local, Mediterranean, and European) of Kok et al. (2006). Our method differs from theirs by linking bespoke national and regional scenarios to off-the-shelf global narratives provided by the SSPs (Kriegler, et al., 2014; O'Neill, et al., 2015).

The paper contributes to the literature by presenting regional socio-economic scenarios specifically for SIDS, that are compatible with both global climatic (RCPs) and socio-economic pathways (SSPs) using a cross-scale, mixed method approach. In addition, it seeks to apply the cross-scale scenarios at the national level to analyze the impact of different futures on water demand. The paper proceeds as follows. In Section 2 how foresight scenarios are used as a methodological tool is reviewed. Section 3 outlines the cross-scale scenario methodology used in the study and an abridged version of the scenarios are presented in Section 4 . Section 5 demonstrates how the scenarios were used to assess future water demand. Section 6 concludes.

\section{Foresight as a research method}

Strategic foresight - thinking in a structured way about the future in order to improve current decision-making - encompasses a variety of tools and methods (Glenn \& Gordon, 2009). Scenarios are arguably one of the most popular foresight techniques. (Durance \& Godet, 2010). Since at least the 1970s (Dror, 1970), research on how we can and do think about the future has been termed "Futures Studies". Subsequent work has explored both the conceptual underpinnings and practice of futures studies (Bell, 1997; Masini, 2010). Conceptualizing the future as something that could exist suggests that it can be the subject of study and research (Maze, 2019). In this paper we are most concerned with foresight techniques as a research tool, rather than as a subject of research itself. Thus, we use foresight techniques - specifically, scenario method - to gain insight into current and prospective social and economic conditions in the Caribbean from people within the region. Scenarios are thus a methodology that contributes

\footnotetext{
${ }^{1}$ The English-speaking Caribbean in this study refers to Caribbean Community (CARICOM) member countries.
} 
to research and can complement other more established research methods (Ramirez, et al., 2015)

\subsection{Scenarios as a research tool}

Imagining the future is a defining human characteristic (Poli, 2011). Humans routinely engage in scenario-building to navigate the future and minimize adverse outcomes. The practice of scenario development was made popular with the publication of "Limits of Growth" by Meadow et al. (1972). Since then, the development of contrasting archetypal scenarios has involved the extraction of quantitative information via analytical and modelling techniques, and the qualitative elaboration of this information integrating levels of uncertainty and complexity (see Figure 2). The respective narratives describe "significantly different, plausible, and future-oriented phenomena in the external environment" (Fergnani \& Jackson, 2019) projecting on to the scenarios the driving forces and emergent issues with cohesive results and evidence from a variety of sources. Understanding the possible futures and their driving forces has become a tool in policy development, assisting in identifying possible solutions to problems through the recognition of uncertainty (Perez-Soba \& Maas, 2015).

Figure 2: Scenario Possibility Space of Complexity and Uncertainty (Zurek \& Heinrichs, 2007)

The practice of scenario development fosters creative thinking, and in doing so stimulates discussion. Informed by those discussions, participants in the process can seek to avoid adverse outcomes and move toward desirable ones. Three types of foresight scenarios have been identified, extrapolatory, exploratory, and pathways to normative or desired futures. Within this work we have adopted the explorative approach, in line with that adopted in the development of the SSPs.

In developing scenarios, five steps have been identified (Schwartz \& Ogilvy, 1998): problem characterization - what is at stake; problem conceptualization - identification of drivers; scenario framing - what is the logic; scenario description - bringing it to life and; scenario assessment what are the options and how do they play out? Depending on the degree of uncertainty regarding the knowledge of outcomes and of likelihood, various computational tools can be invoked and some form of modelling is usually involved to a greater or lesser degree to assist in assessing and/or framing complex interactions (Perez-Soba \& Maas, 2015; Alcamo, 2008).

\subsection{Cross-scale Foresight Scenarios}

Scenarios are mainly constructed at specific geographical scales (Zurek \& Heinrichs, 2007), however the interconnected and integrated nature of issues such as climate change require analysis of change processes and relationships across scales (Biggs, et al., 2007; Zurek \& Heinrichs, 2007). The continuing increase of greenhouse gas emissions is expected to have adverse localized impacts on SIDS including sea level rise linked with beach erosion and saline intrusion of freshwater aquifers, more frequent stronger hurricanes and prolonged periods of drought. Hence, the importance of devising scenarios which are consistent with global projections, while being relevant to local policy makers. Stakeholders at the local level should have some 
degree of control over the system which they are making decisions about (Biggs, et al., 2007). Global scenarios are inadequate if used in isolation, particularly at the SIDS levels where many constraining factors (environment, economic and social) are within their immediate environs.

The need for effective techniques for cross or multiscale scenarios is now well-recognized (Rothman, et al., 2014; Biggs, et al., 2007), and several authors have made contributions (Kok, et al., 2007; Zurek \& Heinrichs, 2007; Stratigea \& Giaoutzi, 2012; Dermawan, et al., 2013). Producing cross-scale scenarios does present challenges; scenarios at different levels may have different objectives and may render the results incompatible and difficult to integrate, the loss of credibility at one scale or the other where specificity or relevance are competing factors and limitations of narrative variety and lack of transferability due to ensuring consistency (Biggs, et al., 2007; Kok, et al., 2007).

At present, there is active exploration of effective methods for cross-scale scenario development, with no consensus on a preferred method. In their seminal paper on scenario linkages, Zurek and Heinrichs (2007) proposed that scenarios can be linked across scales in two ways; through process, and through element/outcomes. Similarly, Biggs, et al. (2007) classified scenarios as either single-scaled or multiscale either 'loosely' linked or 'tightly coupled'. The authors concluded that each type of scenario scale has its merit, and which scale(s) the researcher choses should be based on the objective of the scenario. Schweizer and Kurniawan (2016) further advanced linking the qualitative elements of scenarios through a formal approach-nested dissection, in cross impact matrices, known as linked cross impact balance (CIB). Through linked CIB, the authors were able to isolate zero elements in matrices, 'partition' non-zero matrices and distil across scale and scale specific influences. The authors thereby produced scenarios at a 'sub-scale' that were internally consistent with its parent matrix.

Studies using cross-scale scenarios span several areas including agriculture (Dermawan, et al., 2013) and food security, land degradation, ecosystem services (Kok, et al., 2007) and energy (Trutnevyte, et al., 2014). Few studies have focused on scenarios at the small-island state level that are linked to global scenarios such as the SSPs. A formative SIDS multiscale scenario exercise was carried out for Caribbean islands based on Global Environment Change on Food Systems (GECAFS, 2006; Vervoort, et al., 2014). Also, Royuela and Buckingham (2018) developed foresight scenarios to inform the planning of sustainable development for the Azores islands using a participative multi-criteria mapping approach. However, the regional scenarios were not linked to global scenarios.

There appears to be limited studies on foresight scenarios at the SIDS scale, particularly in the global south, that are linked to global scenarios. Moreover, the application of such integration across scales to inform local level activity is even more scarce. This study seeks to provide a case study in these two areas.

\section{Methodology}

The construction of cross-scale scenarios, within the context of SIDS, faces significant methodological challenges. SIDS, as mentioned in Section 1 have limited resources and sparse and incomplete data, both historical and current, which are sporadic and often missing (UN OHRLLS, 2011). Modelling of economies in SIDS is limited (but see Ronson, 2014; UNECLAC, 2014) and the constraints and opportunities posed by small size and openness are not well captured in global economic models. Regional interlinkages are often strong (e.g. CARICOM in 
the Caribbean, and the Pacific Community in the Pacific) but individual states have significant local differences in culture, history, economies and society, often due to their unique colonial histories (Bolland, 1998; Stewart, 2007). This means that although the distilling of global scenarios down to the regional level is essential, it is not sufficient. A full cross/multiscale exercise in translating global situations down to national levels is preferred in order to understand how future global changes may affect the societies of island states. To go even further the scenarios are used to model future tourism water demand in the small island of Barbados to demonstrate the efficacy of scenarios as a support tool for decision making.

As noted in the review of the literature above, there already exist examples and methods for cross-scale analysis. However, the need is clear but there is not yet a consensus on methodologies and there may never be such because of the diverse needs of local studies linked to global scenarios. The method devised in this study was driven by two considerations. First, there is considerable heterogeneity across CARICOM member states, yet also a (political and social) CARICOM identity. Second, global climate scenario processes can be drawn from and informed from a SIDS perspective. The first consideration led to the two-way split between regional and national scenarios. The second led to a particularly novel approach for linking national and global scenarios.

Certainly, causal influences flow much more strongly from global to local scale. Yet, as is shown using a Bayesian methodology, if you cannot divide global trends from local observation, then it must follow that trends in local areas can diverge substantially from global trends. That frees up the local scenario development process. Therefore, local scenarios are emphasized. Once those have been identified, a question is inspired by Bayesian reasoning, how well aligned are they with global narratives.

\subsection{The 'linking' process}

A three-stage process was used to develop scenarios for the Caribbean for the time horizon 2050. Regional scenarios were 'up-linked' to global scenarios (SSPs) and 'downscaled' to country-level storylines. 'Partially' consistent and complementary (Zurek \& Heinrichs, 2007) regional scenarios were constructed by first using an independent process, followed by an iterative one. Each stage of the methodology fuses specific methods (Table 1). The process follows a stepwise approach with feedback loops at each stage (Figure 3)

Figure 3: Methodological Framework 
Table 1: Three-Staged Linking and Methods

\subsection{Methodological coherence}

In the multi-method approach proposed, a natural question is whether the combination of methods is coherent. The aim is "triangulation"; that is, compensating for weaknesses of one method by introducing a complementary method at each stage. Concerns have been raised about triangulation when using methods that were developed with different ideas about the nature of reality (ontology) and human understanding of reality (epistemology) (Blaikie, 1991). A pragmatic approach is adopted, as suggested by Seale (1999), seeking to increase the breadth and depth of the study, thereby presenting a fuller picture (Fielding \& Fielding, 1986). This is a desirable goal for a foresight study. Each of the steps and the methods used are discussed next.

\subsection{Stage 1- Developing regional scenarios}

First, draft regional scenarios were developed. Three methods were used to craft these scenarios: a review of pertinent regional and global literature, interviews with regional experts and a scenario workshop that combined an intuitive logics approach with cross-impact balances.

To gather contextual information a literature review of 150 articles including peer-review and grey literature was done. Following the review, nine semi-structured stakeholder interviews were carried by the research team with regional experts, who represented various socioeconomic and environmental disciplines, over five weeks and interviewees were asked about future trends in relation to water resources management, climate change, economics, youth, political studies, civil society and environmental development. The findings of the interviews included the identification of future key drivers, critical uncertainties (CUs), sustainable development goals and possible wild card events specific to the Caribbean.

Subsequent to the interviews, a two-day scenario workshop was held with thirty-five pan Caribbean participants. The participants engaged in a brainstorming activity similar to the first steps of a conventional intuitive logics activity (Huss \& Honton, 1987; Amer, et al., 2013) focused on the historical development of the Caribbean. Participants were invited to provide causal statements (which contained drivers), as well as policy levers and goals. The causal statements which ranked as high uncertainty and high impact were then identified as CUs. These CUs were combined with the interview findings and participants finalized the list of CUs with the assistance from the scenario team.

On day two, participants prepared the inputs to the CIB analysis (Weimer-Jehle, 2006). Participants identified possible future values for the CUs; the values assigned, while short were qualitatively comprehensive. In plenary, the participants determined the strength of impact of each 
$\mathrm{CU}$ value on all other $\mathrm{CU}$ values using the Scenario Wizard computer program, which implements the CIB technique. ${ }^{2}$

The CIB exercise produced 15 consistent scenarios. These were analyzed to remove duplication, as well as, scenarios that although quantitatively 'balanced', were not plausible within the Caribbean context. This process resulted in 5 consistent regional scenarios, based on $11 \mathrm{CUs:}$ Governance, Economic Growth, Investment, Export Demand, Income Inequality, Global Economy, Consumption Patterns, Population Growth, Sophisticated Crime, Rate of Technological Adoption and Regional integration.

\subsection{Up-linking to global}

Within the Caribbean, being embedded in a larger economic and political milieu is a reality. Much of the region's colonial history, extending into the early years of independence, the economic and political trajectories of the Caribbean islands closely tracked developments in the "metropole" (Beckford, 1972). However, after independence those links began to weaken, such that the Caribbean is influenced by developments in both North and South America, the EU, and even China, rather than specific metropolitan counterparts (Byron, 2018). To link the regional scenarios to the SSPs, Bayes' Rule (Stone, 2013) was employed. Although simplistic in nature, the rule allows for the identification of the probability of occurrence of one outcome (here, a regional scenario) given another outcome (a global scenario).

\section{Bayesian Probability Rule}

The above observations suggest that cross-scale links can be expressed as conditional tendencies. Conditional because developments at one scale provide a context and impetus for developments at another; tendencies because the links are not deterministic. If tendencies can be assigned probabilities, then we can think in terms of conditional probabilities, an approach that has been taken in past efforts to link qualitative and quantitative scenario elements (O'Neill, 2004; van Vuuren, et al., 2008). If objectively measured probabilities are not available, then there are techniques to elicit subjective probabilities (O'Hagan, et al., 2006), and these techniques can also be used to generate parameter values from qualitative storylines (Alcamo, 2008; Kemp-Benedict, 2010). In this study linking narratives at different scales is the aim, rather than forging links between qualitative and quantitative analyses. In generating a suitable question, Bayes' rule is written in this context as

$$
\frac{P(\text { regional narrative } \mid \text { global narrative })}{P(\text { regional narrative })}=\frac{P(\text { global narrative } \mid \text { regional narrative })}{P(\text { global narrative })} .
$$

Following convention, $P$ indicates a probability, while a vertical line indicates a conditional statement, the equation is read as, "The increase (decrease) in probability that the regional narrative holds true given the global narrative is equal to the increase (decrease) in probability that the global narrative holds true given the regional narrative." This equality means that we can elicit the strength of local-to-global links starting with either the global or regional narrative as the condition.

This might seem surprising; how could a global narrative possibly depend on what happens in the Caribbean? Yet, Bayes' rule, which follows from elementary rules of probability, says that it must. Global conditions certainly impinge upon the small areas, so there is a tendency to assume that global scenarios map one-to-one onto local scenarios.

\footnotetext{
${ }^{2}$ Available from http://www.cross-impact.de/index.htm
} 


\begin{abstract}
But small areas also have a great deal of autonomy. To take one example, a global recession due to a trade war between the United States and China, driven by nationalist impulses, would almost certainly affect tourism revenues in the Caribbean. Yet, the ultimate driver - the turn towards nationalism - need not be part of the Caribbean narrative. Turned the other way, a narrative in which the Caribbean tourism sector is booming would make us doubt a scenario of global recession - not in a causal sense, but because of correlations. The establishment of a generous and outward looking welfare state in a Caribbean nation would tell us very little about global governance trends.
\end{abstract}

To retain 'autonomy' of the regional scenarios from the global scenarios, the regional narratives are imposed as the condition and the question is asked: "Given the region is scenario $X$, how surprised would you be to discover that the world is experiencing global scenario $Y$ ?" As noted above, this runs counter to the strongest causal link, and so creates a feeling of dissonance, encouraging the respondent to stop and think before replying. By using the language of surprise, respondents do not need to make a quantitative judgement. This procedure is meant to elicit a rough assessment of the ratio on the right-hand side of the equation above - that is, the boost in plausibility of a global narrative given regional conditions.

To link the five qualitative regional scenarios to global scenarios and to determine quantitative indicators, the Bayesian conditional probability approach was done using the SSPs (O'Neill, et al., 2017; Riahi, et al., 2017). The SSP conditions of Latin America and the Caribbean middleincome countries, particularly Barbados, Grenada, Jamaica and Trinidad and Tobago were used as references for the regional scenarios. The regional scenario $\mathrm{CU}$ values and middle income country SSPs indicators were then assessed based on proximate conditional probabilities using five categories for the degree of surprise: very likely to occur; somewhat likely to occur; indifferent; not likely to occur; and not at all likely to occur. An example of the exercise is given in Table 2.

Of the five regional scenarios, four matched closely (Very Likely to Occur or Somewhat Likely to Occur) in at least three CUs, in relation to the seven SSPs indicators. One scenario was not identified as matching closely to any of the five SSPs, and on investigation shared some similarity to another regional scenario. These two scenarios were merged and by including information from stage one, a "wild card" scenario was developed. This exercise allowed the integration of SSPs and regional narratives to give form and elaboration to the scenarios at the global and regional levels.

Table 2: Example of Bayesian 'up-linking' exercise

\title{
3.5 Downscaling regional scenarios to national storylines
}

The regional scenarios, linked to global pathways (SSPs) and climate projections (RCPs), were downscaled for Barbados, Jamaica, Trinidad and Tobago and Carriacou ${ }^{3}$. The purpose of the process was two-fold: the first was to create consistent national storylines that highlight specific circumstances that may cause national-level differences in the scenarios; and the second was to feed information from these specific national circumstances into the refinement of the regional scenarios to ensure that they were both linked to local circumstances. This process was

\footnotetext{
${ }^{3}$ Carriacou is a part of the tri-island state of Grenada.
} 
conducted via three methods - an e-Delphi, analysis of regional case studies and the development of national-level macroeconomic system dynamic models.

A two-round e-Delphi was conducted over a two-month period. The purpose of the e-Delphi was to assess the regional scenarios at the national level to identify island idiosyncrasies. Experts from across the Caribbean (Barbados, Trinidad, Jamaica, Bahamas and Grenada) participated. The respondents represented diverse professional backgrounds including economics, environmental studies, water resources management, government and public policy, and disaster risk management. The average self-assessment level of expertise of participants was 4 on a scale of 1-amateur to 5-expert.

Four questionnaires were produced to elicit information, one for each country given a regional scenario - essentially four distinct country-scenario combinations were chosen so that the country-scenario possibility space could be covered efficiently without the production of a large number of surveys. Consensus was determined by cumulative frequency using the criteria of a 60 percent or greater rate, less than 60 percent was considered non-consensus. Overall, consensus between rounds was determined by means and standard deviation convergence indicators (Cole, et al., 2013; Donohoe, et al., 2012). Findings from the e-Delphi were used to elaborate national storylines using country-specific information.

To reinforce and enhance the plausibility of the national storylines, proxy case studies were identified with similar current and historical experiences. Where no suitable case-study was available from within the Caribbean, the experience of countries from beyond the region were chosen. The identification of each case-study was based on the scenario team's experience and focusing on typical, most-similar examples following established approaches for case-study selection (Mabry, 2008; Seawright \& Gerring, 2008). Case-studies from Guyana (for the period 1975 to 1989), Jamaica, Iceland and Mauritius (present day) were chosen and key features, experiences and data were drawn from literature. This allowed for granularity and richness within the storylines.

To test and illustrate the scenarios narratives a macroeconomic model was developed and applied to Barbados, Jamaica, and Trinidad and Tobago (see Kemp-Benedict, Drakes and Laing, (2018) for full elaboration of the model). The macroeconomic model was conceptually constructed to strengthen, as well as illustrate, the changing dynamics within the socio-economic storylines. Three major constraints were: 1) the specific features of small, open developing economies; 2) the data available for calibration and hypothesis-testing; and 3) correspondence between model inputs and scenario narrative elements, particularly the critical uncertainties. Figure 4 depicts the logic of the systems model developed for the study. ${ }^{4}$

Figure 4: Macroeconomic Model (Kemp-Benedict, et al., 2018)

To further cross check the scenarios and quantitative projections, a second workshop was held with 25 professionals from the region. The purpose was to refine the scenarios and identify any internal inconsistencies using a participatory approach. More specifically, it was to formally

\footnotetext{
${ }^{4}$ The model is in the Caribbean structuralist tradition, while drawing on recent developments in structuralist theory. It is driven by external demand for exports, which then provide wages and demand for domestic goods, which adds to existing domestic demand. The focus is on the external balance, giving GDP, net imports, and cumulative external debt. The model for Barbados has recently been updated: see Kemp-Benedict et al. (2020).
} 
engage key stakeholders on the scenarios and garner feedback on the narratives and foster ownership. This evaluation led to the inclusion of additional trends, an examination of potential policy implications and a prominent change; an extension of one of the regional scenario storylines.

\subsection{Applying Scenarios to Model Future Water Demand}

The regional scenarios developed were used to create national storylines for Barbados, Jamaica, Trinidad and Tobago and Carriacou. The case of Barbados is used to illustrate the implications of regional and global climatic and socio-economic changes on small island economic activity -tourism and natural resources - freshwater. The national level storylines were used to investigate future water demand in Barbados' tourism sector by answering the question; "How would these different sets of socio-economic conditions shape tourism water demand?" National storylines set out the inferred level of economic activity, types of economic activity, level of technological innovation, demographic profiles, institutional arrangements, all of which influence the socio-economic environment within which the tourism sector operates, and what and how water services are provided. Barbados tourism is being used as a case study to highlight how the modelling of scarce natural resources, such as freshwater, within varying socio-economic and climate scenarios can provide useful insights for policy-makers. Moreover, water demand in the tourism sector was analyzed for three specific reasons. One, the tourism sector is the main economic driver for Barbados and the majority of Caribbean SIDS (Jessop, 2017). Two, the tourism sector has a significantly higher unit water consumption as compared to domestic consumption (Charara, et al., 2011) and therefore its management is critical to the viability of the sector. Lastly, most Caribbean SIDS already face challenges in meeting existing water demands. The application of scenarios to assess key development issues, such as water availability, can be a valuable decision support process that identifies robust policy options (Volery \& Ribeiro, 2009).

To estimate tourism's future water demand, the underlying driver behind water demand was considered - stay-over tourist numbers. Therefore, in order to estimate tourism water demand, the number of tourist arrivals are estimated under the different future foresight scenarios, scenarios that are driven by both SSPs and RCPs. In order to provide quantitative answers for this question future tourist water demand was modelled for the narrative scenarios that were developed. In order to do this, the national storyline narratives with their respective socio-economic scenarios were mapped on to the RCPs. As discussed below in Section 4 there are different socio-economic scenarios for any given RCP. Down-scaled climate data ${ }^{5}$ was then mapped on to each narrative to give a numerical estimate of key climate variables (temperature, humidity, precipitation) for each future scenario. This information was then used to drive the economic modelling described in the following paragraph.

Various approaches to understanding what might drive tourist numbers have been advanced in the literature, based on a range of economic determinants such as income in source country, relative price, cost of travel and exchange rate. The Tourist Comfort Index (Mieczkowski, 1985) (TCl) which includes climatic variables (temperature, humidity, precipitation etc.) recognizes climate as being an important determinant to travel. Moore (2010) integrated the TCI into a crosscountry Caribbean tourism demand model. The model not only incorporated relative changes

\footnotetext{
${ }^{5}$ Downscaled climate data provided by Professor John Agard, University of the West Indies, St Augustine, Trinidad.
} 
in climate variables between source and host countries but also included economic variables, for example, relative changes and differences in GDP between source and host countries. It also draws on work that inter-relates assumed SSPs and economic parameters such as GDP with RCPs. So that future climatic conditions, depending on the assumed RCP, have associated parameters such as GDP, which are used as inputs to the $\mathrm{TCl}$ and hence anticipate the effects of climate change on tourist arrivals. The derived $\mathrm{TCl}$ will differ depending on which combination of SSPs, regional scenarios and RCPs is considered. The model adopted here follows this approach in first estimating a historical relationship between $\mathrm{TCl}$ and other socio-economic conditions and tourist numbers, and then using this relationship to project future patterns, using down-scaled climate data and projections from economic modelling. The approach is described below.

1. A relationship between climatic and socio-economic conditions was estimated using regression analysis upon historical data from across the Caribbean. A causal relationship between the $\mathrm{TCl}$ in the destination country, the $\mathrm{TCl}$ in source countries (proxied by the United States), the GDP per capita in the destination country, the GDP in the source country (proxied by the United States), relative exchange rate, and the number of stayover tourists was found.

2. This relationship was used to estimate future stay-over tourist numbers in Barbados within the different regional scenarios by drawing on down-scaled climate data for the respective RCPs from and macro-economic data relating to the regional scenarios based upon the economic system dynamic modelling.

3. The number of stayover tourists was incorporated into modelling different components of water demand in the tourist sector in Barbados, based on models from previous research on Barbados hotels' water demand characteristics (Charara, et al., 2011).

4. Estimates of future water demand for the different future scenarios were derived.

Schematically the process is shown in Figure 5, below.

Figure 5: Relationship between SSPs, RCPs National Storylines, Total Comfort Index and Future Water Demand

\section{Caribbean Scenarios 2050}

Below is a synopsis of each regional scenario, see Drakes, et al. (2016) for a full elaboration.

Regional Scenario 1 “Cool Runnings” (SSP 2)- In 2050 globalization persists and regional integration thrives with Trinidad and Jamaica being the leaders in external trade from the region. The role of government is significantly reduced, and private-public partnerships dominate the provision of social services such as health, education and transport. There is moderate economic growth with foreign investment facilitating many new projects around the region. Despite the upward growth trend income inequality contributes to the challenge of reducing poverty. The region has an energy mix of fossil fuel and renewable energy consumption however, renewable energy has a larger and growing share in the market. Although there is growing acceptance of renewable energy, economic prosperity is paramount and environmental issues are raised only 
when (i) crises occur and environmental policy is reactive to major events or (ii) when there is economic viability to exploit natural resources for profit.

Regional Scenario 2 "Island in the Sun" (SSP 1)- Over industrialization and mass levels of pollution from the major economies cause a drastic shift in lifestyles aimed at reclaiming the earth's natural state. This revolution sparks rapid investment in renewable energy. Globally, it has been mandated that all countries conform to the use of renewables and this change promotes large multilateral funded projects centered on renewable energy. The Caribbean is fully integrated, and its energy production is driven mainly by renewable energy sources. Health and wellness tourism and the recycling and reuse industry are key sectors. Societies shift away from the "need" for material wealth and possessions with greater emphasis on physical and mental well-being. Communities engage in 'time banking' to trade goods and services. Traditional parliamentary systems exist within a regional agenda aligned with a focus that renewable energy and "green" industries are the best option for Caribbean sustainability.

Regional Scenario 3 "Harder they Come" (SSP 3)- At the global level regional rivalry is increasing, compounded by weak coordination among global institutions. Protectionist policies become more widely used at the regional and national level with a focus on security and food imports. The Caribbean economies struggle to maintain economic growth and are characterized by obsolete economic sectors. Many countries have increased demand for foreign goods, this along with slow growth result in high debt levels. Governance is centralized with only political officials and technocrats formally being involved in policymaking. However, technology allows for citizens to organize mass rallies to place pressure on those in power in order to influence policy.

Regional Scenario 4 "Pirates of the Caribbean" Pathway 1 (SSP 4)- The collapse of the US economy pushes most of the world into an economic depression. Global institutions have been disbanded due to high distrust between countries and border security is critical to protecting limited resources. Before the collapse, countries were focused on reaching new "global commons" however, investment shifts towards military and defense budgets. The slowdown in the global economy negatively impacts the Caribbean economies. Reduced investment and limited job opportunities push many persons into poverty. Increased trafficking of drugs and arms create unstable societies where crime is prevalent. There is little focus on environmental conservation.

Regional Scenario 4 "Pirates of the Caribbean" Pathway 2 (SSP 4)- The economic depression negatively affects the Caribbean economies however, the crisis creates the necessary expediency and political momentum for regional integration to become a reality, with rapid moves to economic and political integration. Public investment at both the regional and national level focuses on security. Strong regional coordination keeps the worst excesses of crime abated. The financial investment that is required in this area reduces financing to social services such as health and education. Governance is relatively transparent with a regional focus and acts of corruption occur infrequently but are policed and sanctioned severely. Regional cohesion is founded on the Trinidadian and Jamaican cultural influence which predominate through the strong economic and political power they hold.

The four RCPs have no socio-economic narratives attached to them, rather they reflect the expected impact of different assumptions about the volume of greenhouse gasses emitted. Conversely, the five SSPs each incorporate assumptions regarding population and economic growth, levels of education, degree of urbanization, and rate of technological development and were developed to reflect different societal choices. These choices were used to infer how they might affect greenhouse gas emissions. The SSPs provide a flexible description of possible futures within each RCP. Each of the regional scenarios described above were 'up-linked' to the global scenarios (SSPs). As with the SSPs, the assumptions within each of the Regional 
Scenarios span across different emission scenarios; there is no unique incidence of a regional scenario with a particular combination of SSP and RCP. In other words, given the underlying assumptions, different regional scenarios can lead to similar volumes of emissions i.e. RCPs. Figure 6 shows the mapping of the regional scenarios onto the RCPs and SSPs space.

Figure 6: Relationship between Scenarios, SSPs and RCPs

\section{Application of Foresight Cross-Scale Scenarios}

Barbados is a small island in the Eastern Caribbean (Figure 1) with a population of approximately 280,000 and a land area of $430 \mathrm{~km}^{2}$.It is a classified as a middle-income economy with a GDP per capita of US\$18,500 (World Bank, 2019) dominated by the tourism sector (Central Bank of Barbados, 2019). Tourism contributes $13 \%$ to GDP directly and is the largest private sector employer accounting for over $20 \%$ of the workforce (World Travel and Tourism Council, 2018). Barbados is the $15^{\text {th }}$ most water scarce country in the world, it is almost entirely reliant on groundwater for its water supply and it is estimated that the country utilizes almost $100 \%$ of its renewable water resources (Cashman, et al., 2010). Drought conditions in 2009/10 and 2017 onward, have highlighted issues of water availability and have led to restrictions on water supplied.

Tourism's water demand accounts for approximately $15 \%$ of the total amount of water supplied by the Barbados Water Authority (Cashman, et al., 2012) and further, per capita, hotel tourists consume on average 3.6 times more than domestic consumers (Charara, et al., 2011). This is a significant portion of the overall water demand and is reinforced when tourism demand peaks during the dry months of the year, placing additional demand on the supply system. The few studies that are available have indicated that the impact on water availability is highly dependent on the selection of the climate change scenario; under RCP 8.5 the impacts on available water to meet demand are particularly severe (Gohar, et al., 2019).

Understanding the demand side is important for developing future policies and development planning - including tourism. How will climate change influence tourism water demand under different future foresight scenarios? The way global climate scenarios and contrasting foresight scenarios of regional/local socio-economic realizations lead to different outcomes in terms of tourist water demand is illustrated by the following example. As per Figure 5 the global emissions scenario for RCP4.5 was mapped onto three different regional scenarios, which are, as explained, based on the downscaled SSPs. This therefore provides an interesting exercise to demonstrate the importance of the socio-economic scenarios. Hotel water demand is estimated under the three applicable regional scenarios and using RCP4.5. The differences between the scenarios are therefore not climatic, but socio-economic - such as wealth of tourists, GDP differences between source and host country, and changes in efficiency of water use under the socio-economic scenarios. The results are shown in Table 3 and it should be stressed that these results are indicative. 
Table 3: Hotel Water Demand in different Regional Scenarios under RCP 4.5

The results indicate the extent to which different socio-economic conditions have an impact on the relative difference in hotel water demand. In this case, there is $17 \%$ difference between the highest and lowest estimated water demand. The highest demand occurs in the scenario in which technological change is likely to be the slowest, increasing assumed losses in the system and low rates of adoption of water savings technologies. Wealth differences between the source and host country for tourists is also large in this scenario - implying the relative price of tourism is low - encouraging greater tourist numbers. The scenario with the lower water demand reflects the greater technological improvements and lower overall wealth differentials leading to smaller tourist numbers. The results support an intuitive appreciation that, ceteris paribus, varying socio-economic pathways exert a major influence on the level of demand of natural resources such as water. This variance has implications for water resource planning and highlights the need for robust adaptation options for decision making. This crystallizes the necessity of not only developing climatic pathways, but the need to develop plausible socio-economic scenarios at varying scales. Interestingly, the results under the same socio-economic conditions but different emissions scenario, shows there are only minor differences between the estimated hotel demands. Therefore, changes in socio-economic conditions have a proportionately greater influence than climate change scenarios in this context.

\section{Discussion}

The findings provide methodological, contextual and practical implications for global to island cross scaling scenario development.

\subsection{Methodological considerations}

The scenario process, despite the various distinct techniques for 'linking', proved arduous and required expert decision-making throughout the process. Although each step outlined specific techniques to be used, a 'sub-layer' of decision making proved necessary. During the e-Delphi only one regional scenario was assigned to a country based on country-scenario affinity. This pairing could have only been done with intimate knowledge of each island state. Limited participants and geographical dispersion required bespoke steps within the methodology to retain robustness yet be flexible enough to accommodate the unique regional dynamics of the island states.

Given the prevalence of downscaling in the literature, a proposed 'up-linking' process is described in some detail. The process respects the autonomy of the regional scenario. Despite employing a rudimentary mathematical principle, transposing the conditionality of scenario occurrence prompts cognitive reasoning when assessing regional and global interactions. Greater use of mathematical principles or other techniques (Schweizer \& Kurniawan, 2016; Kemp-Benedict, et al., 2019) can be used to 'link' elements across scales removing some ambiguity of the process.

\subsection{Future Island Societies}

Linking SIDS with global pathways resulted in innovative societal structures being proposed. New plausible governance (reduced role of government with strong regional integration - Scenario 1), and economic systems (time banking - Scenario 2) and wild cards (Scenario 4) are revealed. Assessing the Caribbean region through these possible structures and events expands thinking 
on the possibility space of the future for islands. Traditional planning and adaptation approaches which incorporate alternative, uncertain systems and events could inform more robust policy options across a wider spectrum of future states. Wise, et al., (2014) suggested that with respect to climate change, uncertainties associated with institutions and social aspects are just as important to consider as uncertainties around climate science and predictions. Based on this it is imperative that islands states envision future societies bound within climate projections to uncover adaptation and responses appropriate for their context.

\subsection{Application of Cross-Scale Scenarios}

Using socio-economic scenarios to investigate natural resource implications can further highlight the difference between resource demand, not just within varying climatic scenarios, but within varying societal contexts. The range of potential water demand in Barbados under varying socioeconomic structures allows for a fuller investigation of the possible tools and responses policymakers could devise to respond to changes in resource demand. The broader possibility space prompts not just the enquiry into the viability of satisfying water demand but also, the structure of the sector (mass tourism vs eco-tourism) and the overall economy (transition from tourism dependent economy to more diverse economic activities). This emphasizes the strengths of investigating the future under divergent, but not mutually exclusive futures. Scenarios therefore provide policy makers with mental models and a structured way of exploring the future. They allow for strategy development and the necessary actions to be taken to achieve desired outcomes or mitigate against risks (Ringland, 1998; 2010). In SIDS where public funding is limited scenarios present a tool of efficiency given the opportunity arises for them to be included in public policy decision making.

\section{Conclusion}

The paper presents a three staged linking approach to develop socio-economic scenarios for the Caribbean region in 2050, which included up-linking to global scenario elements (SSPs \& RCPs) and downscaling to create national storylines. It demonstrates that it is possible to develop plausible regional scenarios and national storylines that are internally logical and consistent with global climate and social scenarios. Furthermore, the methods used are robust and coherent. To demonstrate scenario value in policy making, the scenarios were used to assess water demand in the Barbados tourism sector. A framework is provided for integrating quantitative principles with qualitative techniques to add richness and depth to the foresight scenarios. The four regional scenarios developed, uncover new socio-economic structures that can be used to broaden the possibility space of decision making in Caribbean SIDS.

This case study is a first step in understanding how cross-scale foresight scenarios can be developed for and applied to small island states. Applying cross-scale scenarios to activities in productive industries and in the management of natural resources in SIDS are areas of future research worthy of exploration. Also, how future scenarios differ from existing socioeconomic systems and the transformative actions needed to support sustainable policy decisions will be critical research in the future. How strategic foresight can be used to inform policy planning within a SIDS context given their unique characteristics is an opportunity for researchers and added-value for policy makers. Moreover, investigation into 
the socio-economic structures that are climate compatible is needed, along with the understanding the efficacy of using scenarios across policy spaces to inform adaptation, mitigation, and resilience planning strategies.

\section{References}

Alcamo, J., 2008. Chapter Six The SAS Approach: Combining Qualitative and Quantitative Knowledge in Environmental Scenarios. In: J. Alcamo, ed. Environmental Futures - The Practice of Environmental Scenario Analysis. s.I.:Elsevier, pp. 123-150.

Amer, M., Daim, T. U. \& Jetter, A., 2013. A review of scenario planning. Futures, Volume 46, pp. 23-40.

Beckford, G., 1972. Persistent Poverty: Underdevelopment in Plantation Economies of the Third World. Oxford: Oxford University Press.

Bell, W., 1997. Foundations of Futures Studies: Human Science for a New Era. New Brunswick, NJ, US: Transaction Publishers.

Bell, W. \& Wilson, E., 1998. Back From Chaos. s.I.:The Atlantic Monthly.

Biggs, R. et al., 2007. Linking Futures across Scales: A Dialog on Multiscale Scenarios. Ecology and Society, 12(1).

Blaikie, N. W., 1991. A critique of the use of triangulation in social research. Quality and Quantity, 25(2), p. 115-136.

Bolland, O. N., 1998. Creolisation and Creole Societies: A Cultural Nationalist View of Caribbean Social History. Caribbean Quarterly, 44(1/2), pp. 1-32.

Byron, J., 2018. The Contemporary Crisis in Globalization and its impact on Latin America with special reference to the Caribbean region of Latin America. Buenos Aires, CRIES.

Cascio, J., 2012. Bad Futurism, San Francisco: s.n.

Cashman, A., Cumberbatch, J. \& Moore, W., 2012. The effect of Climate Change on Tourism in small states: evidence from the Barbados case. Tourism Review, 67(3), pp. 17-29.

Cashman, A. et al., 2016. Modelling the Impact of Climate Change in a Water Scarce Island: Tourism Water Demand Projections, Bridgetown: University of the West Indies.

Cashman, A., Nurse, L. \& Chalery, J., 2009. Climate Change in the Caribbean: The Water Management Implications. The Journal of Environment \& Development, pp. 42-67.

Cashman, A., Nurse, L. \& Charlery, J., 2010. Climate Change in the Caribbean: The Water Management Implications. Journal of Environment and Development, 19(1), pp. 42-67.

Central Bank of Barbados, 2019. Barbados Economic Review Jan-June 2019, Bridgetown: Central Bank of Barbados.

Charara, N., Cashman, A., Bonnell, R. \& Gehr, R., 2011. Water use efficiency in the hotel sector of Barbados. Journal of Sustainable Tourism, 19(2), p. 231-245. 
Cole, Z., Donohoe, H. M. \& Stellefson, M., 2013. Internet-Based Delphi Research: Case Based Discussion. Environmental Management, 51(3), pp. 511-523.

de Freitas, C. R., Scott, D. \& McBoyle, G., 2008. A second generation climate index for tourism (CIT): specification and verification. International Journal of Biometeorology, 52(5), pp. 399-407.

Dermawan, A., Kemp-Benedict, E., Huber-Lee, A. \& Fencl, A., 2013. Testing a multi-scale scenario approach for smallholder tree plantations in Indonesia and Vietnam. Technological Forecasting \& Social Change, 80(4), pp. 762-771.

Djalante, R., 2019. Key assessments from the IPCC special report on global warming of $1.5^{\circ} \mathrm{C}$ and the implications for the Sendai framework for disaster risk reduction. Progress in Disaster Science, Volume 1.

Donohoe, H., Stellefson, M. \& Tennant, B., 2012. Advantages and Limitations of the e-Delphi Technique: Implications for Health Education Researchers. American Journal of Health Education, 31(1), pp. 38-46.

Drakes, C., Laing, T., Kemp-Benedict, E. \& Cashman, A., 2016. Caribbean Scenarios 2050, s.I.: CERMES Technical Report 84.

Dror, Y., 1970. A policy sciences view of future studies: Alternative futures and present action. Technological Forecasting and Social Change, 2(1), pp. 3-16.

Durance, P. \& Godet, M., 2010. Scenario building: Uses and abuses. Technological Forecasting and Social Change, 77(9), pp. 1488-1492.

Fergnani, A. \& Jackson, M., 2019. Extracting scenario archetypes: A quantitative text analysis of documents about the future. Futures \& Foresight Science, 1(e17), pp. 1-34.

Fielding, N. \& Fielding, J., 1986. Linking Data. Thousand Oaks, CA, US: SAGE Publications, Inc.

Gallopin, G. C. \& Raskin, P., 1998. Windows on the Future: Global Scenarios \& Sustainability. Environment: Science and Policy for Sustainability, 40(3), pp. 6-11.

GECAFS, 2006. A Set of Prototype Caribbean Scenarios for Research on Global Environmental Change and Regional Food Systems, Wallingford, UK: Global Environmental Change and Food Systems.

Glenn, J. C. \& Gordon, T. J., 2009. Futures Research Methodology Version 3.0. Washington, DC, US: The Millennium Project.

Gohar, A., Cashman, A. \& Ward, F., 2019. Managing Food and Water Security in Small Island States: New Evidence from Economic Modelling of Climate Stressed Groundwater Resources. Journal of Hydrology, Volume 569, pp. 239-251.

Huss, W. R. \& Honton, E. J., 1987. Scenario planning - What Style Should You Use. Long Range Planning, 20(4), pp. 21-29.

Jessop, $2017 . \quad$ D., Caribbean Council. [Online] Available at: https://www.caribbean-council.org/tourism-vital-caribbean-economy/ [Accessed 29 January 2020].

Kelman, I. \& West, J., 2009. Climate Change and Small Island Developing States: A Critical Review. Ecological and Environmental Anthropology, 5(1), pp. 1-16. 
Kemp-Benedict, E., 2010. Converting Qualitative Assessments to Quantitative Assumptions: Bayes' Rule and the Pundit's Wager. Technological Forecasting and Social Change, 77(1), pp. 167-171.

Kemp-Benedict, E., Drakes, C. \& Canales, N. 2020. "A Climate-Economy Policy Model for Barbados." Economies 8 (1): 16. https://doi.org/10.3390/economies8010016.

Kemp-Benedict, E., Drakes, C. \& Laing, T., 2018. Export-led Growth, Global Integration and the External Balance of Small Island Developing States. Economies, p. 35.

Kemp-Benedict, E., Lamontagne, J., Laing, T. \& Drakes, C., 2019. Climate Impacts on Capital Accumulation in the Small Island State of Barbados. Sustainability, 11(11), p. 3192.

Kok, K., Biggs, R. \& Zurek, M., 2007. Methods of Developing Multiscale Participatory Scenarios: Insights from Southern Africa and Europe. Ecology \& Society, 12(1), pp. 1-16.

Kok, K., Patel, M., Rothman, D. S. \& Quaranta, G. 2006. "Multi-Scale Narratives from an IA Perspective: Part II. Participatory Local Scenario Development." Futures 38 (3): 285-311. https://doi.org/10.1016/j.futures.2005.07.006.

Kriegler, E. et al., 2014. A New Scenario Framework for Climate Change Research: The Concept of Shared Climate Policy Assumptions. Climatic Change, 122(3), pp. 401-14.

MA Scenarios Working Group, 2005. Ecosystems and Human Well-Being: A Framework for Assessment. Washington D.C,: Island Press for the Millenium Ecosystem Assessment.

Mabry, L., 2008. Case Study in Social Research. In: P. Alasuutari, L. Bickman \& J. Brannen, eds. The SAGE Handbook of Social Research Methods. London, UK: SAGE Publications.

Masini, E. B., 2010. The past and the possible futures of Futures Studies: Some thoughts on Ziauddin Sardar's 'the namesake'. Futures, 42(3), pp. 185-189.

Maze, R., 2019. Politics of designing visions of the future. Journal of Future Studies, 23(3), pp. 23-38.

Meadow, D., Meadow, D., Randers, J. \& Behrens, W., 1972. Limits to Growth. New Work: Universe Books.

Mieczkowski, Z., 1985. The tourism climatic index: A method of evaluating world climates for tourism. The Canadian Geographer, 29(3), pp. 220-233.

Moore, W., 2010. The impact of climate change on Caribbean tourism demand. Current Issues in Tourism, pp. 495-505.

Nakicenovic, N. et al., 2000. Special Report on Emissions Scenarios - SRES Final Data (Version 1.1. July 2000), The Hague: Intergovernmental Palenl on Climate Change.

O'Hagan, A. et al., 2006. Uncertain Judgements: Eliciting Experts' Probabilities. Chichester, UK: John Wiley \& Sons, Ltd.

O'Neill, B. C., 2004. Conditional Probabilistic Population Projections: An Application to Climate Change. International Statistical Review, 72(2), pp. 167-184.

O'Neill, B. et al., 2015. The Roads Ahead: Narratives for Shared Socioeconomic Pathways Describing Futures in the 21st Century. Global Environmental Change. 
O'Neill, B. et al., 2017. The Roads Ahead: Narratives for Shared Socioeconomic Pathways Describing Futures in the 21st Century. Global Environmental Change, Volume 42, pp. 169-180.

Perez-Soba, M. \& Maas, R., 2015. Scenarios: tools for coping with complexity and future uncertainty. In: The Tools of Policy Formulation: Actors, Capacities, Venues and Effects, New Horizons in Public Policy Series. Cheltenham, UK: Edward Elgar, pp. 52-75.

Poli, R., 2011. Steps towards an explicit ontology of the future. Journal of Future Studies, Volume 16, pp. 67-78.

Ramirez, R., Mukherjee, M., Vezzoli, S. \& Kramer, A., 2015. Scenarios as scholarly methodology to produce "interesting research". Futures, Volume 71, pp. 70-87.

Raskin, P., 2008. World Lines: A Framework for Exploring Global Pathways. Ecological Economics, 65(3), pp. 461-470.

Rhiney, K., 2015. Geographies of Caribbean Vulnerability in a Changing Climate: Issues and Trends. Geography Compass, 9(3), p. 97-114.

Riahi, K. et al., 2017. The Shared Socioeconomic Pathways and their energy, land use, and greenhouse gas emissions implications: An overview. Global Environmental Change , 42(09593780), pp. 153-168.

Ringland, Gill. 1998. Scenario Planning Managing for Future. West Sussex: John Wiley and Sons.

Ringland, Gill. 2010. "The role of scenarios in strategic foresight." Technological Foresight and Social Change 77 (9): 1493-1498.

Robinson, S., 2018. Adapting to climate change at the national level in Caribbean small island developing states. Island Studies Journal, 13(1), pp. 79-100.

Ronson, R., 2014. Development of a modelling framework in support of an assessment of the economic and social impacts of climate change in the Caribbean: the ECLAC - CIAM Model. ECLAC series, p. 31.

Rothman, D. S., Romero-Lankao, P., Schweizer, V. J. \& Bee, B. A., 2014. Challenges to adaptation: a fundamental concept for the shared socio-economic pathways and beyond. Climatic Change, 122(3), pp. 495-507.

Royuela, J. B. \& Buckingham, S., 2018. Transitions to sustainability in small islands: combining foresight scenarios with multi-criteria analysis to develop viable sustainability strategies in an EOR. International Journal of of Sustainable Development and World Ecology, pp. 1-9.

Schwartz, p. \& Ogilvy, J., 1998. Plotting your scenario. In: Learning from the Future. New York: John Wiley \& Sons, pp. 57-80.

Schweizer, V. \& Kurniawan, J., 2016. Systematically linking qualitative elements of across levels, scales and sectors. Environmental Modelling \& Software, pp. 322-333.

Scupelli, P., Wasserman, A. \& Brooks, J., 2016. Dexign Futures: A pedagogy for long-horizon design scenarios. Brighton, UK, s.n., pp. 1-16.

Seale, C., 1999. Quality in qualitative research. Qualitative Inquiry, 5(4), pp. 465-478.

Seawright, J. \& Gerring, J., 2008. Case Selection Techniques in Case Study Research: A Meun of Qualitative and Quantitative Options. Political Research Quarterly, 61(2), pp. 294-308. 
Stewart, C., 2007. Creolization: History, Ethnography, Theory. Walnut Creek, CA: Left Coast Press Inc..

Stone, J., 2013. Bayes' Rule: A Tutorial Introduction to Bayesian Analysis. 1st ed. Warszawa: Sebtel Press.

Stratigea, A. \& Giaoutzi, M., 2012. Linking Global to Regional Scenarios in Foresight. Futures, 44(10), pp. 847-59.

Taylor, M. et al., 2018. Future Caribbean Climates in a World of Rising Temperatures: The 1.5 vs 2.0 Dilemma. American Meteorological Society, Volume 31, pp. 2907-2926.

Trutnevyte, E. et al., 2014. Linking a storyline with multiple models: A cross-scale study of the UK power system transition. Technological Forecasting and Social Change, pp. 26-42.

UN OHRLLS, 2011. Small Island Developing States: Small Islands Big(ger) Stakes, s.I.: United Nations.

UNECLAC, 2014. The Economics of Climate Change in the Caribbean, Port of Spain, Trinidad and Tobago: United Nations Economic Commission for Latin America and the Caribbean Subregional Headquarters for the Caribbean.

UNEP, 2007. Global Environmental Outlook GEO4: Environment for Development. Valetta, Malta: Progress Press Ltd. for the United Nations Environmental Programme.

UNEP, 2010. Global Environmental Outlook GEO5: Environment For the Future We Want. Nairobi, Kenya: United Nations Environmental Programme.

UNEP, 2019. The Emissions Gap Report, Nairobi: United Nations Environment Programme.

UNFCCC, 2007. Vulnerability and Adaptation to Climate Change in Small Island Developing States, s.I.: UNFCCC.

Vaha, M. E., 2018. Hosting the Small Island Developing States: two scenarios. International Journal of Climate Change Strategies and Management, 10(2), pp. 229-244.

van Vuuren, D. P., de Vries, B., Beusen, A. \& Heuberger, P. S. C., 2008. Conditional Probabilistic Estimates of 21st Century Greenhouse Gas Emissions Based on the Storylines of the IPCCSRES Scenarios. Global Environmental Change, Volume 18, pp. 635-654.

Vervoort, J. M. et al., 2014. Challenges to scenario-guided adaptive action on food security under climate change. Global Environmental Change, pp. 383-394.

Volery, A. \& Ribeiro, T., 2009. Scenario planning in public policy: Understanding use, impacts and the role of institutional context factors. Technological Forecasting \& Social Change, Volume 76, pp. 1198-1207.

Weimer-Jehle, W., 2006. Cross-Impact Balances: A System-Theoretical Approach to CrossImpact Analysis. Technological Forecasting and Social Change, 73(4), pp. 334-361.

Wilbanks, T. J. \& Kates, R. 1999. "Global Change in Local Places: How Scale Matters." Climatic Change 43 (3): 601-28. https://doi.org/10.1023/A:1005418924748.

Wise, R. et al., 2014. Reconceptualizing adaptation to climate change as part of pathways of change and response. Global Environmental Change, Volume 28, pp. 325-336. 
WMO, 2019. WMO Provisional Statement on the State of the Global Climate in 2019, Geneva: World Meteorological Organization.

World Bank, 2019. World Bank Databank. [Online] Available at: https://data.worldbank.org/indicator/SP.POP.TOTL?locations=BB\&view=chart [Accessed 9 April 2019].

World Travel and Tourism Council, 2018. Travel \& Tourism Economic Impact 2018 Barbados, London: World Travel \& Tourism Council.

Zurek, M. B. \& Heinrichs, T., 2007. Linking Scenarios across Geographical Scales in International Environmental Agreements. Technological Forecasting and Social Change, 74(8), pp. 1282-95. 
Figure 1: The Caribbean Region

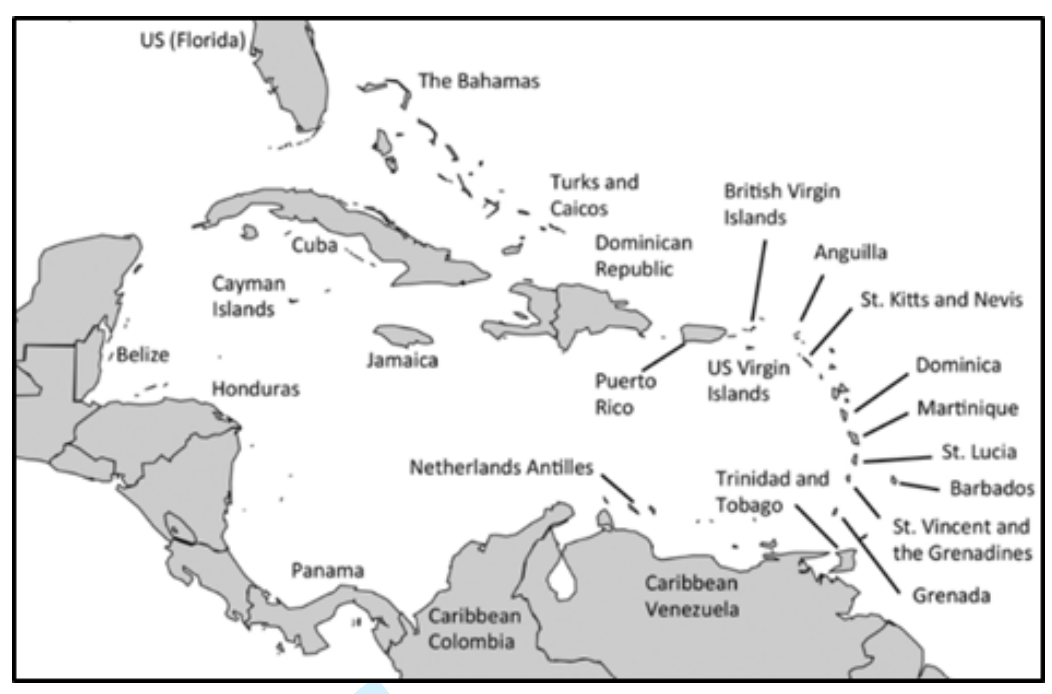

23 
Figure 1: Scenario Possibility Space of Complexity and Uncertainty (Zurek \& Heinrichs, 2007)

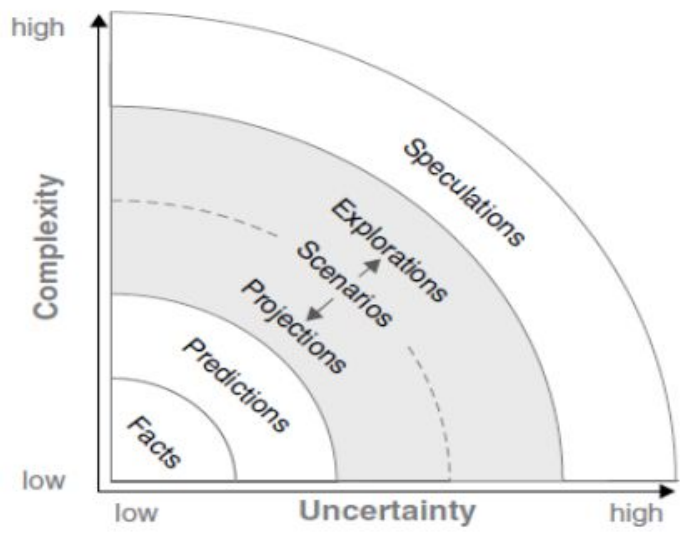


Figure 1: Methodological Framework

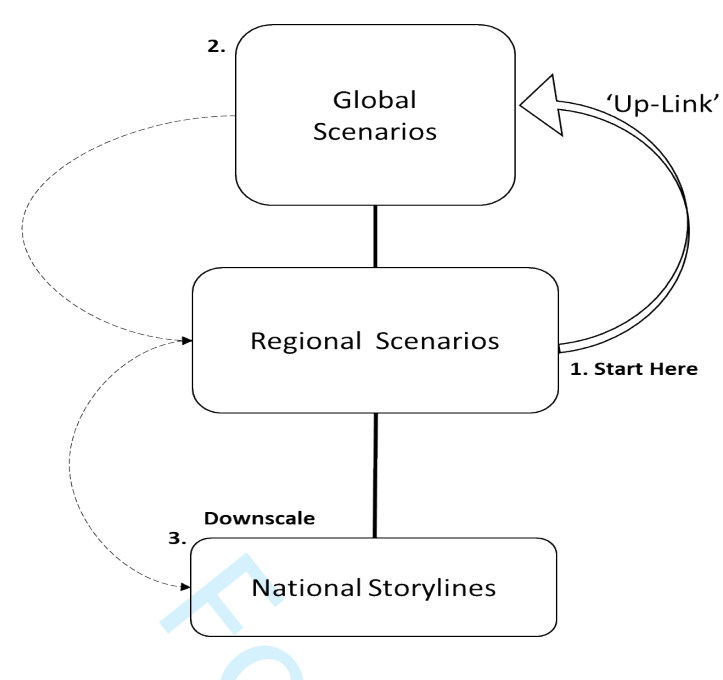


Figure 1: Macroeconomic Model (Kemp-Benedict, et al., 2018)

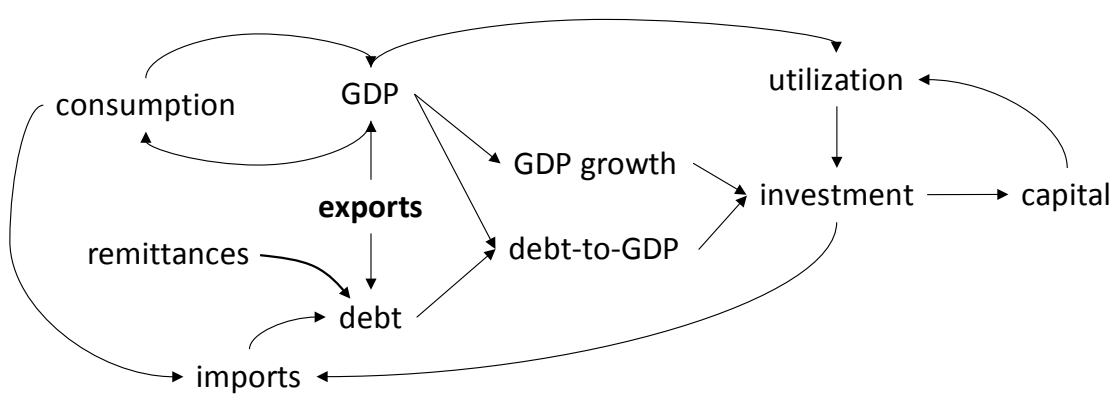


Figure 5: Relationship between SSPs, RCPs National Storylines, Total Comfort Index and Future Water Demand

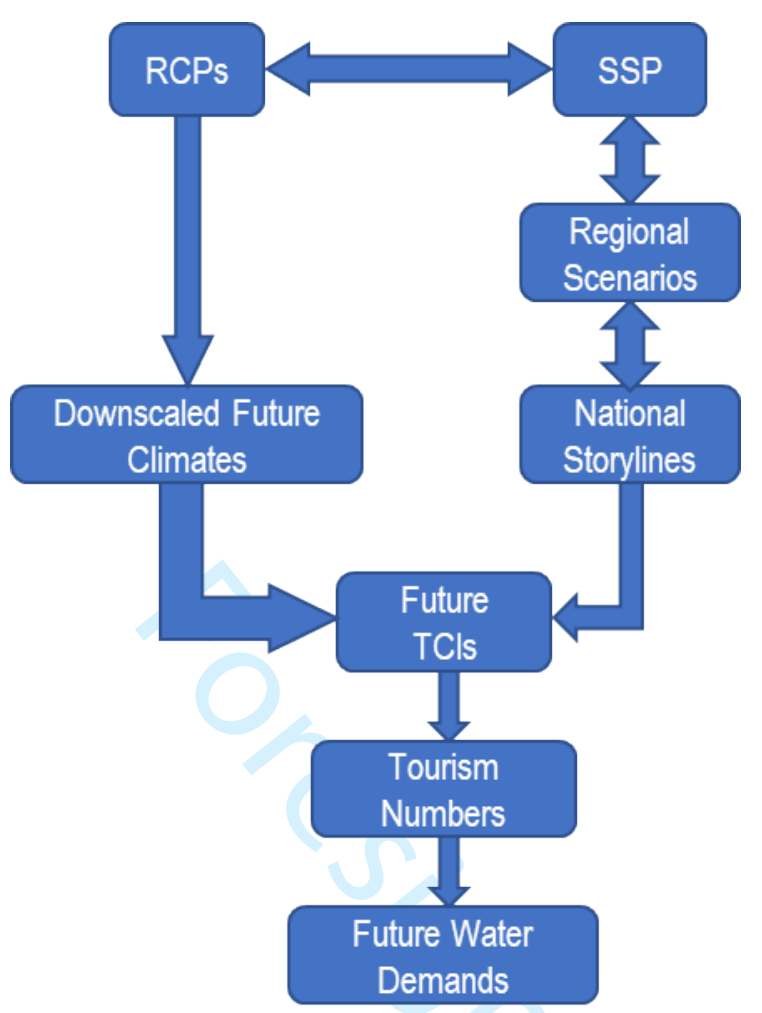


Figure 6: Relationship between Scenarios, SSPs and RCPs

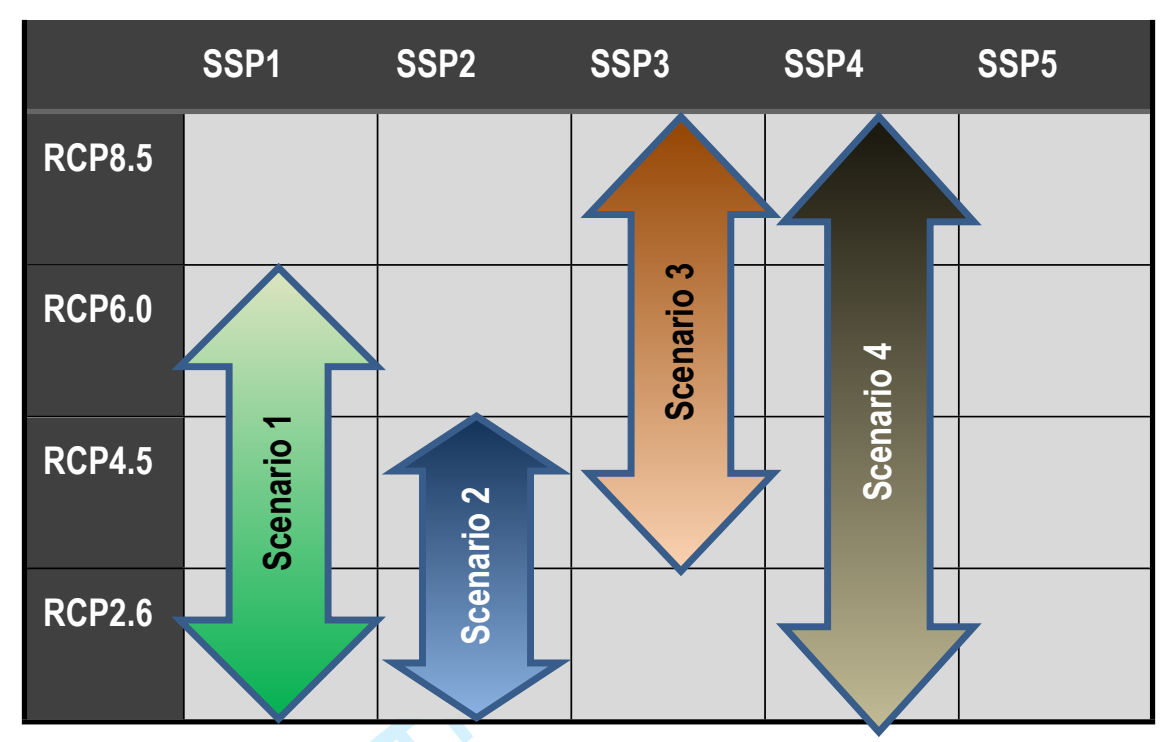


Table 1: Three-Staged Linking and Methods

\begin{tabular}{|c|c|}
\hline Stages & Method \\
\hline Stage 1 - Regional Scenarios & $\begin{array}{l}\text { Literature review } \\
\text { Expert Interviews (Identification of CUs) } \\
\text { Scenario Workshop } 1 \text { (Cross Impact Balance) }\end{array}$ \\
\hline $\begin{array}{l}\text { Stage } 2 \text { - 'Up-linking' from Regional to Global } \\
\text { Scenarios }\end{array}$ & Bayesian Probability Rule \\
\hline $\begin{array}{l}\text { Stage } 3 \text { - Downscaling from Regional to Local } \\
\text { storylines }\end{array}$ & $\begin{array}{l}\text { E-Delphi } \\
\text { Case Study Mapping } \\
\text { Systems Dynamic Modelling } \\
\text { Scenario Workshop } 2 \text { (Participant Feedback) }\end{array}$ \\
\hline
\end{tabular}


1

2

3

4

5

6

7

8

9

10

11

12

13

14

15

16

17

18

Table 1: Example of Bayesian 'up-linking' exercise

\begin{tabular}{|c|c|c|c|c|c|}
\hline $\begin{array}{l}\text { Given Regional Scenario A is } \\
\text { occurring, how would you rank the } \\
\text { occurrence of the following Global } \\
\text { Scenarios? }\end{array}$ & $\begin{array}{c}\text { Very } \\
\text { Likely to } \\
\text { Occur }\end{array}$ & $\begin{array}{c}\text { Somewhat } \\
\text { Likely to } \\
\text { Occur }\end{array}$ & Indifferent & $\begin{array}{c}\text { Not } \\
\text { Likely to } \\
\text { Occur }\end{array}$ & $\begin{array}{c}\text { Not at all } \\
\text { Likely to } \\
\text { Occur }\end{array}$ \\
\hline \multicolumn{6}{|l|}{ SSP 1-Sustainabilty } \\
\hline Pop Growth Relatively Low & \multirow{7}{*}{$\mathbf{X}$} & & & & \\
\hline Globalization Connected Markets & & & & & \\
\hline GDP Growth High & & & & & \\
\hline Inequality Reduced & & & & & \\
\hline Institutions Effective & & & & & \\
\hline Int'I Trade Moderate & & & & & \\
\hline Tech Transfer Rapid & & & & & \\
\hline \multicolumn{6}{|l|}{ SSP 2- Middle of the Road } \\
\hline Pop Growth Medium & & & & \multirow{7}{*}{$\mathbf{X}$} & \\
\hline Globalization Semi-Open & & & & & \\
\hline GDP Growth Medium & & & & & \\
\hline Inequality Uneven & & & & & \\
\hline Institutions Modest Effectiveness & & & & & \\
\hline Int'l Trade Moderate & & & & & \\
\hline Tech Transfer Slow & & & & & \\
\hline
\end{tabular}


Table 1: Hotel Water Demand in different Regional Scenarios under RCP 4.5

\begin{tabular}{lrrr}
\hline \hline Regional Scenario & Cool Runnings & The Harder They Come & Pirates of the Caribbean \\
\hline Hotel Demand $\left(\mathrm{Mm}^{3}\right)$ & 6.120 & 7.190 & 7.010 \\
\hline
\end{tabular}

